\title{
Assessing the Spatial Distribution of Key Flavonoids in Mentha $\times$ piperita Leaves: An Application of Desorption Electrospray Ionization Mass Spectrometry Imaging (DESI-MSI)
}

\author{
Julia R. L. e Freitas, ${ }^{a}$ Pedro H. Vendramini, ${ }^{b}$ Júlio O. F. Melo, ${ }^{\circledR c}$ Marcos N. Eberlin $^{b}$ and \\ Rodinei Augusti ${ }^{\circledR *, a}$
}

${ }^{a}$ Departamento de Química, Universidade Federal de Minas Gerais, 31270-901 Belo Horizonte-MG, Brazil

${ }^{b}$ Laboratório ThoMSon de Espectrometria de Massas, Instituto de Química, Universidade Estadual de Campinas, 13083-970 Campinas-SP, Brazil

'Departamento de Química, Universidade Federal de São João Del Rei, 35701-970 Sete Lagoas-MG, Brazil

\begin{abstract}
Desorption electrospray ionization mass spectrometry imaging (DESI-MSI) was used to assess the spatial distribution of some key flavonoids in peppermint (Mentha $\times$ piperita $\mathrm{L}$.) leaves. The chemical images were generated by applying DESI-MSI on the peppermint leaves imprinting while acquiring the spectra in the negative ion mode. The following key flavonoids were detected and grouped within well-known biosynthetic routes in plants: naringenin route [naringenin, sakuranetin, hesperetin, hesperidin, luteolin, and apigenin]; luteolin route [luteolin, chrysoeriol, luteolin-7- $O$-D-glucuronide, luteolin-7- $O$-D-glucoside, luteolin-7- $O$-neohesperidoside]; apigenin route [apigenin, apigenin-7- $O$-gentiobioside, apigenin-7- $O$-neohesperidoside, thymusin/pilosin, pebrellin, acacetin/genkwanin, ladanein, xanthomicrol/pedunculin/nevadensin]. Maps of the spatial distribution of these flavonoids throughout the peppermint leaves within each route were then displayed. The results described herein comprise an important (although still underexplored) subject that certainly will experience a remarkable growth in the next years.
\end{abstract}

Keywords: peppermint leaves, DESI-MSI, secondary metabolites in plants, metabolic routes

\section{Introduction}

Flavonoids are secondary phenolic metabolites common to all types of plants and biosynthesized via the phenylpropanoid route. These compounds possess fifteen carbons in their structure forming two aromatic rings connected by three carbon units. The main subclasses are: flavonols, flavones, isoflavones, flavanones, dihydroflavonols, flavan-3-ols, chalcones, anthocyanins and aurones. Although distributed in all parts of the plants, these metabolites are mainly concentrated in flowers, fruits and leaves. Flavonoids can also be found as methylated derivatives, i.e., aglycones and glycosides. In glycosides, the most common carbohydrate moieties are L-rhamnose, D-glucose, glucorhamnose, galactose, or arabinose. ${ }^{1-4}$

In plants, flavonoids are responsible for several functions including protection against herbivores and

*e-mail: augusti.rodinei@gmail.com pathogens, nitrogen fixation in roots, attraction of pollinators, protection against oxidation and abiotic stress (caused by high incidence of ultraviolet radiation and changes in ambient temperature and moisture). In addition, flavonoids are responsible for some typical phenotypic features in plants, such as color, fragrance and taste of fruits, flowers, and seeds. . $^{1,25-8}$

Flavonoids are incorporated into the human diet by the ingestion of fruits, flowers, leaves and derivative products. For instance, herbal teas, prepared by the infusion of plant tissues (mainly leaves and flowers) in hot water, are rich in flavonoids and are often used for medicinal purposes. ${ }^{6}$ Usually these compounds are used by humans in therapeutic treatments due to their antioxidant, antibacterial, antiviral, anti-inflammatory and antineoplastic properties. ${ }^{3,6,9,10}$

The medicinal herb Mentha $\times$ piperita L., popularly known as peppermint, belongs to the Lamiaceae family. It is a hybrid species derived from the species Mentha aquatica $\mathrm{L}$. and Mentha spicata L. Peppermint is a perennial herbaceous 
plant, native from Europe, but is currently cultivated worldwide. ${ }^{11,12}$ It exhibits several therapeutic activities like analgesic, antioxidant, anti-inflammatory, anti-allergic, antiviral, fungicidal and bactericidal. It can also be used to treat several diseases, such as gout, and illnesses in the gastrointestinal and respiratory tracts. ${ }^{11-14}$ In peppermint leaves, phenolic compounds correspond to $12 \%$ of the total flavonoids. The main constituents of these compounds are eriocitrin, luteolin-7-rutinoside, esperidoside, total hydroxycinnamic compounds and rosmarinic acid. The infusion of these leaves in hot water can extract $75 \%$ of such phenolic compounds. ${ }^{15}$

The most commonly used technique for the analysis of flavonoids in plant leaves is high performance liquid chromatography (HPLC). Besides requiring the use of assorted solvents to extract the target compounds, ${ }^{9}, 10,12,13,15-19$ this technique does not provide information regarding the spatial distribution of metabolites in plant tissues. In contrast, desorption electrospray ionization (DESI)-mass spectrometry imaging (MSI), a recently-introduced methodology, has been increasingly used for this purpose. ${ }^{20-31}$ This technique uses a DESI source coupled with an automatic mobile platform that enables the attainment of 2D chemical images. Mass spectra (MS) of each surface spot are acquired in the full scan mode and used to generate chemical images of any detectable ionic species. As a consequence, the spatial distribution of (ionizable) organic compounds and their relative intensities directly from a given sample surface, with minimal or no pre-treatment steps, can be achieved. ${ }^{32-35}$

The main objective of the present study is therefore to apply DESI-MSI to visualize the spatial distribution of some key flavonoids in Mentha $\times$ piperita L. leaves and associate these images with the main routes responsible for the biosynthesis of such metabolites in plants. It is important to say that the present manuscript is closely related to a previous work published by our research group ${ }^{20}$ in which we also employed DESI-MSI to examine the source-to-sink relationship in plants by the detection of the main amino acids and sugars in peppermint leaves at three distinct maturation ages (young, intermediate and mature).

\section{Experimental}

\section{Material}

The solvents used, methanol and toluene, both of HPLC grade, were purchased from Tedia (Rio de Janeiro, Brazil). Polytetrafluoroethylene (PTFE) membranes (pore size: $0.45 \mu \mathrm{m}$, diameter: $47 \mathrm{~mm}$ ) were purchased from Allcrom (São Paulo, Brazil).

\section{Sample preparation}

A shrub of Mentha $\times$ piperita L. was purchased at a local store. This species was confirmed by its morphological characteristics. Four leaves were analyzed, but the results presented herein refer to only one of them. A $38 \mathrm{~mm}$ long leaf was removed from the shrub at the time of analysis to avoid any change in its metabolic content.

Sample preparation consisted of only two simple steps. In the first one, the surface wax was removed by washing the leaf with toluene. ${ }^{26,28}$ Because the leaf surface is totally irregular, which causes changes in the incidence angle of the solvent spray and the consequent generation of distorted images, a procedure known as imprinting and recently standardized ${ }^{36}$ was carried out. In this procedure, the peppermint leaf was placed between two PTFE membranes and submitted to a high pressure of a manual press for approximately $60 \mathrm{~s}$. The metabolites were then transferred to the PTFE membranes. The membrane that was in contact with the ab-axial side of the leaf was chosen for the analyses.

\section{DESI-MSI analyses}

DESI-MSI analyses were conducted using an Omni Spray IonSource 2D mobile platform (Prosolia, Indianapolis, USA) coupled to a Thermo Scientific Q Exactive mass spectrometer (Thermo Fisher Scientific, Darmstadt, Germany). The geometric parameters of the source and the mobile platform were adjusted to obtain an optimized response. The typical instrumental parameters were as follows: capillary voltage and temperature, $5 \mathrm{kV}$ and $300{ }^{\circ} \mathrm{C}$, respectively; solvent, methanol; flow rate, $10 \mu \mathrm{L} \mathrm{min}^{-1}$. The MS were acquired in the negative ion mode and in a mass-to-charge ratio $(\mathrm{m} / \mathrm{z})$ range of 100 to 1000 . The images were collected with a resolution of $200 \mu \mathrm{m}$ and a scanning rate of $740 \mu \mathrm{m} \mathrm{s}^{-1}$.

The PTFE membrane was attached to the mobile platform while the DESI spray reached the surface at a point near the entrance of the mass spectrometer. The DESI source works by applying a potential of several $\mathrm{kV}$ on the metallic syringe plunger, which is loaded with a solvent (methanol in the present manuscript). The solvent passes through a probe along with a nebulizer gas and at the end of the probe a spray is formed, which basically contains electrically-charged micro-droplets. The spray is directed to the surface to first cause desorption and solubilization of the analytes, followed by ionization within the released micro-droplets. Subsequent solvent evaporation promotes the coulombic fission of the micro-droplets, thus liberating the ionized analytes into the gas phase, which are directed to the mass spectrometer to be analyzed. The sampling 
area was defined and arranged in a Cartesian plane. The mobile platform moves in the $x$ and $y$ directions and scans the entire sample surface, whereas the mass spectrometer continuously acquires the data at each point. The $x$-axis comprises the directional line in which the mobile platform moves at a constant and predefined rate, whereas the $y$-axis is composed of numerous lines with previously defined spaces between them. As a result of this process, a spatial distribution for any ion in the mass range analyzed can be generated by handling the MS data with the following softwares: ${ }^{32-35}$ mobile platform control (Prosolia Omni Spray 2D, version 2.0.1); MS processing (Xcalibur Qual Browser); conversion of the MS data to 2D ion images (Firefly, version 2.1.05); and visualization and handling of images (BioMAP, version 3.8.04).

Direct infusion electrospray ionization mass spectrometry (DI-ESI-MS) and tandem mass spectrometry (MS/MS) experiments

To prepare the methanolic extracts, $60 \mathrm{mg}$ of leaves were weighed and macerated in $2 \mathrm{~mL}$ of methanol. The extract was analyzed on a Thermo Scientific Q Exactive mass spectrometer (Thermo Fisher Scientific, Darmstadt, Germany). The typical instrumental parameters were as follows: capillary voltage, $5 \mathrm{kV}$; temperature, $300{ }^{\circ} \mathrm{C}$; injection rate, $10 \mu \mathrm{L} \mathrm{min}{ }^{-1}$. The MS were acquired in the negative ion mode and in an $\mathrm{m} / \mathrm{z}$ range of 100 to 1000 .
In the MS/MS experiments, the deprotonated flavonoids were mass-selected and submitted to collision dissociation to obtain the respective product ions. The MS data were treated with the Xcalibur Qual Browser software.

\section{Results and Discussion}

Identification of flavonoids

The flavonoids desorbed from the peppermint leaf imprinting were detected in their deprotonated forms (negative mode) by the high-resolution MS. A typical MS obtained is displayed in Figure 1.

Firstly, the molecular formula for all anions (flavonoids in their deprotonated forms) were proposed based on their exact masses and isotopic distribution patterns. These molecular formula showed errors smaller than $1 \mathrm{ppm}$ for the difference between the theoretical and experimental masses (Table 1). Moreover, the experimental isotopic distributions were shown to be consistent with the calculated profiles. A detailed search in the literature allowed for the proposal of chemical structures for each one of these compounds (Tables 2 and 3). To further support the proposed structures, the dissociation profiles of some deprotonated flavonoids, obtained via DI-ESI-MS analysis of the leaves methanolic extract followed by MS/MS experiments (see Experimental section for more details), were shown to be consistent with those available in the literature..$^{40-45}$

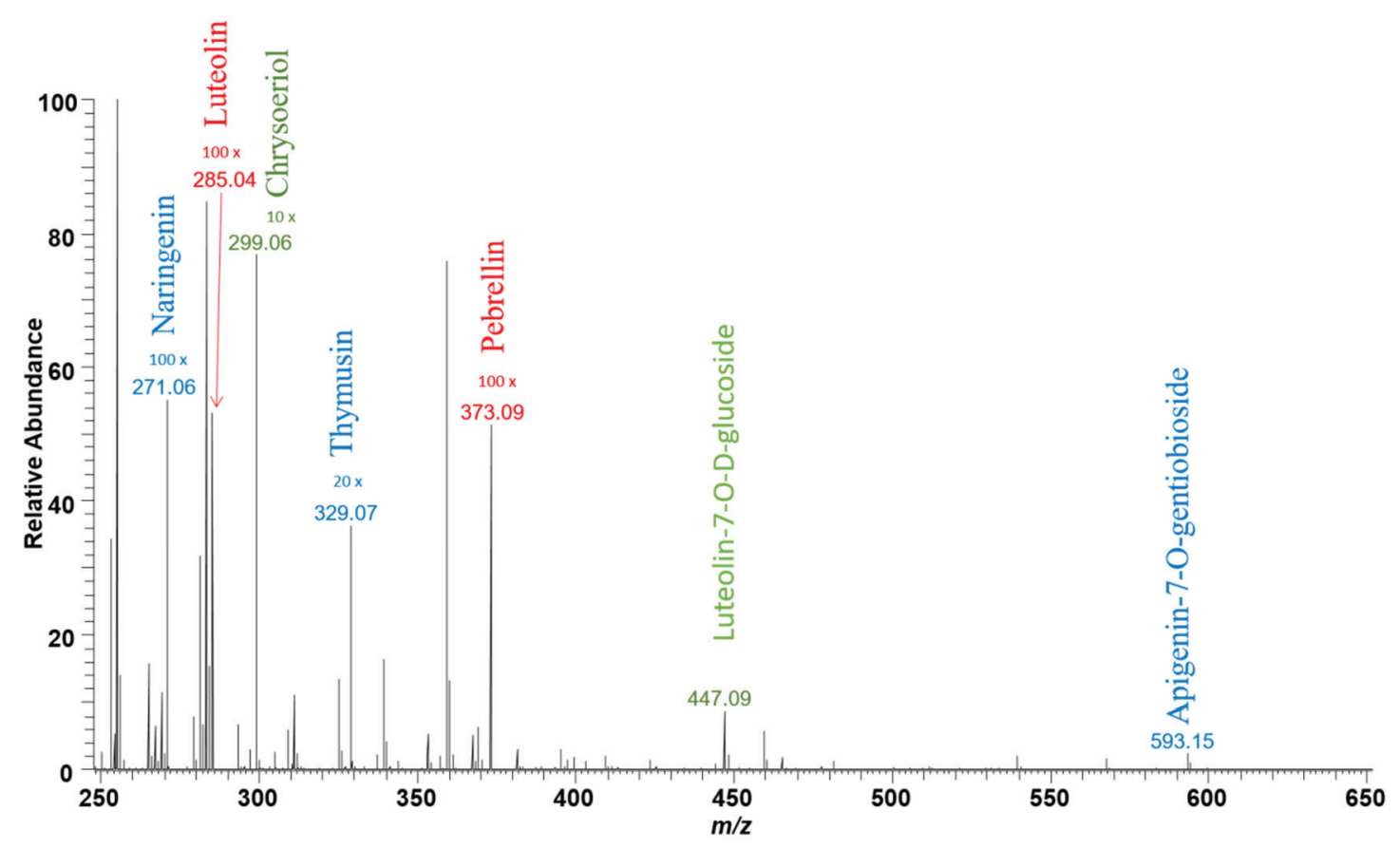

Figure 1. Expanded view (from $\mathrm{m} / \mathrm{z}, 100$ to 650 ) of the average MS (negative ion mode) obtained from the line 51 of the peppermint leaf imprinting. Amplifications, indicated above each anion, were used to facilitate visualization. The $\mathrm{m} / \mathrm{z}$, ratios are indicated above each flavonoid anion. 
Table 1. Flavonoids detected in the peppermint leaf imprinting via DESI-MSI

\begin{tabular}{|c|c|c|c|c|c|}
\hline \multirow{2}{*}{ Flavonoid } & \multirow{2}{*}{$\begin{array}{l}\text { Molecular } \\
\text { formula }\end{array}$} & \multicolumn{2}{|c|}{ Exact mass $^{\mathrm{a}}$} & \multirow{2}{*}{ Error / ppm } & \multirow{2}{*}{ Reference $^{\mathrm{b}}$} \\
\hline & & Theoretical & Experimental & & \\
\hline Naringenin (1) & $\mathrm{C}_{15} \mathrm{H}_{12} \mathrm{O}_{5}$ & 271.06010 & 271.06126 & 0.233 & 9,37 \\
\hline Sakuranetin (2) & $\mathrm{C}_{16} \mathrm{H}_{14} \mathrm{O}_{5}$ & 285.07575 & 285.07686 & 0.046 & - \\
\hline Hesperetin (3) & $\mathrm{C}_{16} \mathrm{H}_{14} \mathrm{O}_{6}$ & 301.07066 & 301.07174 & -0.071 & 12 \\
\hline Hesperidin (4) & $\mathrm{C}_{28} \mathrm{H}_{34} \mathrm{O}_{15}$ & 609.18140 & 609.18195 & -1.617 & $6,9,37$ \\
\hline Luteolin (5) & $\mathrm{C}_{15} \mathrm{H}_{10} \mathrm{O}_{6}$ & 285.03936 & 285.04054 & 0.276 & $6,12,37-39$ \\
\hline Apigenin $(\mathbf{6})$ & $\mathrm{C}_{15} \mathrm{H}_{10} \mathrm{O}_{5}$ & 269.04445 & 269.04566 & 0.421 & $12,38,39$ \\
\hline Chrysoeriol (7) & $\mathrm{C}_{16} \mathrm{H}_{12} \mathrm{O}_{6}$ & 299.05501 & 299.05611 & -0.004 & 14 \\
\hline Luteolin-7-O-D-glucuronide (8) & $\mathrm{C}_{21} \mathrm{H}_{18} \mathrm{O}_{12}$ & 461.07145 & 461.07238 & -0.356 & 6 \\
\hline Luteolin-7-O-D-glucoside (9) & $\mathrm{C}_{21} \mathrm{H}_{20} \mathrm{O}_{11}$ & 447.09219 & 447.09329 & 0.012 & 6,13 \\
\hline $\begin{array}{l}\text { Luteolin-7- } O \text {-neohesperidoside (10)/apigenin- } \\
\text { 7-O-gentiobioside (11) }\end{array}$ & $\mathrm{C}_{27} \mathrm{H}_{30} \mathrm{O}_{15}$ & 593.15010 & 593.15121 & 0.028 & 6,12 \\
\hline Apigenin-7-O-neohesperidoside (12) & $\mathrm{C}_{27} \mathrm{H}_{30} \mathrm{O}_{14}$ & 577.15518 & 577.15633 & 0.089 & 12,13 \\
\hline Thymusin (13)/pilosin (14) & $\mathrm{C}_{17} \mathrm{H}_{14} \mathrm{O}_{7}$ & 329.06558 & 329.06613 & -0.383 & $6,18,38,39$ \\
\hline Pebrellin (15) & $\mathrm{C}_{19} \mathrm{H}_{18} \mathrm{O}_{8}$ & 373.09179 & 373.09279 & -0.270 & $6,13,18,38,39$ \\
\hline Acacetin (16)/genkwanin (17) & $\mathrm{C}_{16} \mathrm{H}_{12} \mathrm{O}_{5}$ & 283.06010 & 283.06065 & 0.047 & $6,12,38,39$ \\
\hline Ladanein (18) & $\mathrm{C}_{17} \mathrm{H}_{14} \mathrm{O}_{6}$ & 313.07066 & 313.07162 & -0.452 & $6,38,39$ \\
\hline Xanthomicrol (19)/pedunculin (20)/nevadensin (21) & $\mathrm{C}_{18} \mathrm{H}_{16} \mathrm{O}_{7}$ & 343.08123 & 343.08222 & -0.309 & $6,12,38,39$ \\
\hline
\end{tabular}

aDeprotonated form; ${ }^{b}$ references that mention the occurrence of these flavonoids in Mentha $\times$ piperita.

Table 2. Chemical structures proposed for the flavanones identified in the peppermint leaf imprinting via DESI-MSI

Flavanone<smiles>[R7]c1cc(O)c2c(c1)OC(c1ccc([R5])c([R2])c1)CC2=O</smiles>

\begin{tabular}{lccc}
\hline Compound & $\mathrm{R}_{1}$ & $\mathrm{R}_{2}$ & $\mathrm{R}_{3}$ \\
\hline Naringenin (1) & $\mathrm{OH}$ & $\mathrm{H}$ & $\mathrm{OH}$ \\
Sakuranetin (2) & $\mathrm{OCH}_{3}$ & $\mathrm{H}$ & $\mathrm{OH}$ \\
Hesperetin (3) & $\mathrm{OH}$ & $\mathrm{OH}$ & $\mathrm{OCH}_{3}$ \\
Hesperidin (4) & $O$-rutinosyl & $\mathrm{OH}$ & $\mathrm{OCH}_{3}$ \\
\hline
\end{tabular}

Note that the ions displayed in Table 1 are barely detectable in the DESI MS (see, for instance, Figure 1). In spite of their very low relative intensities, these ions produced high-quality DESI images, as will be presented later in this manuscript. It is also important to state that naringenin (1), hesperidin (4), luteolin (5), apigenin (6) and its glycosylated derivatives, some of the flavonoids listed in Table 1, are the main secondary metabolites found in peppermint leaves. ${ }^{6,9,10,13,16,37-39}$ Some flavonoids hold an isomeric relationship and evidently could not be differentiated by their exact mass. Because of that, these flavonoids are grouped together in Table 1, such as: (i) thymusin (13)/pilosin (14); (ii) acacetin (16)/genkwanin (17); (iii) xanthomicrol (19)/pedunculin (20)/nevadensin (21); and (iv) luteolin-7-O-neohesperidoside (10)/apigenin7-O-gentiobioside (11). Moreover, Tables 2 and 3 display the chemical structures of these flavonoids grouped according to their classification as flavanones and flavones. It is important to clarify that Mentha $\times$ piperita and other plants from the same family (Lamiaceae) do not produce isoflavones, for instance genistein and its derivatives. ${ }^{46} \mathrm{In}$ contrast to the other classes of flavonoids, the taxonomic distribution of isoflavones is restricted. Except for very few exceptions, isoflavones occur exclusively in plants of the Fabacea family (for instance, soybean, beans, and other grains). Because of that, the presence of isoflavones in the peppermint leaves were not considered herein, only flavanones and flavones (Table 3). Moreover, the possibility of differentiating among the several isomeric flavonoids (Table 1) by means of their fragmentation profiles (MS/MS experiments) was also attempted (some dissociation spectra are displayed as Figure S1, Supplementary Information section). However, the very small intensities of such ions 
Table 3. Chemical structures proposed for the flavones identified in the peppermint leaf imprinting via DESI-MSI

\begin{tabular}{|c|c|c|c|c|c|c|c|}
\hline & & $\mathrm{R}_{1}{ }^{\prime \prime}$ & $\mathrm{R}_{5}^{\prime \prime}$ & & & & \\
\hline Compound & $\mathrm{R}_{1}$ & $\mathrm{R}_{2}$ & $\mathrm{R}_{3}$ & $\mathrm{R}_{4}$ & $\mathrm{R}_{5}$ & $\mathrm{R}_{6}$ & $\mathrm{R}_{7}$ \\
\hline Luteolin (5) & $\mathrm{OH}$ & $\mathrm{H}$ & $\mathrm{OH}$ & $\mathrm{H}$ & $\mathrm{OH}$ & $\mathrm{OH}$ & $\mathrm{H}$ \\
\hline Apigenin $(6)$ & $\mathrm{OH}$ & $\mathrm{H}$ & $\mathrm{OH}$ & $\mathrm{H}$ & $\mathrm{H}$ & $\mathrm{OH}$ & $\mathrm{H}$ \\
\hline Luteolin-7-O-D-glucuronide (8) & $\mathrm{OH}$ & $\mathrm{H}$ & $O$-glucuronide & $\mathrm{H}$ & $\mathrm{H}$ & $\mathrm{OH}$ & $\mathrm{OH}$ \\
\hline Chrysoeriol (7) & $\mathrm{OH}$ & $\mathrm{H}$ & $\mathrm{OH}$ & $\mathrm{H}$ & $\mathrm{OCH}_{3}$ & $\mathrm{OH}$ & $\mathrm{H}$ \\
\hline Luteolin-7-O-D-glucoside (9) & $\mathrm{OH}$ & $\mathrm{H}$ & $O$-glucoside & $\mathrm{H}$ & $\mathrm{H}$ & $\mathrm{OH}$ & $\mathrm{OH}$ \\
\hline Luteolin-7-O-neohesperidoside (10) & $\mathrm{OH}$ & $\mathrm{H}$ & $O$-neohesperidoside & $\mathrm{H}$ & $\mathrm{H}$ & $\mathrm{OH}$ & $\mathrm{OH}$ \\
\hline Apigenin-7-O-gentiobioside (11) & $\mathrm{OH}$ & $\mathrm{H}$ & $O$-gentiobioside & $\mathrm{H}$ & $\mathrm{H}$ & $\mathrm{OH}$ & $\mathrm{H}$ \\
\hline Apigenin-7- $O$-neohesperidoside (12) & $\mathrm{OH}$ & $\mathrm{H}$ & $O$-neohesperidoside & $\mathrm{H}$ & $\mathrm{H}$ & $\mathrm{OH}$ & $\mathrm{H}$ \\
\hline Thymusin (13) & $\mathrm{OH}$ & $\mathrm{OH}$ & $\mathrm{OCH}_{3}$ & $\mathrm{OCH}_{3}$ & $\mathrm{H}$ & $\mathrm{OH}$ & $\mathrm{H}$ \\
\hline Pilosin (14) & $\mathrm{OH}$ & $\mathrm{OCH}_{3}$ & $\mathrm{OH}$ & $\mathrm{OH}$ & $\mathrm{H}$ & $\mathrm{OCH}_{3}$ & $\mathrm{H}$ \\
\hline Pebrellin (15) & $\mathrm{OH}$ & $\mathrm{OH}$ & $\mathrm{OCH}_{3}$ & $\mathrm{OCH}_{3}$ & $\mathrm{H}$ & $\mathrm{OCH}_{3}$ & $\mathrm{OCH}_{3}$ \\
\hline Acacetin (16) & $\mathrm{OH}$ & $\mathrm{H}$ & $\mathrm{OH}$ & $\mathrm{H}$ & $\mathrm{H}$ & $\mathrm{OCH}_{3}$ & $\mathrm{H}$ \\
\hline Genkwanin (17) & $\mathrm{OH}$ & $\mathrm{H}$ & $\mathrm{OCH}_{3}$ & $\mathrm{H}$ & $\mathrm{H}$ & $\mathrm{OH}$ & $\mathrm{H}$ \\
\hline Ladanein (18) & $\mathrm{OH}$ & $\mathrm{OH}$ & $\mathrm{OCH}_{3}$ & $\mathrm{H}$ & $\mathrm{H}$ & $\mathrm{OCH}_{3}$ & $\mathrm{H}$ \\
\hline Xanthomicrol (19) & $\mathrm{OCH}_{3}$ & $\mathrm{OCH}_{3}$ & $\mathrm{OCH}_{3}$ & $\mathrm{OH}$ & $\mathrm{H}$ & $\mathrm{OH}$ & $\mathrm{H}$ \\
\hline Pedunculin (20) & $\mathrm{OH}$ & $\mathrm{OCH}_{3}$ & $\mathrm{OCH}_{3}$ & $\mathrm{OH}$ & $\mathrm{H}$ & $\mathrm{OCH}_{3}$ & $\mathrm{H}$ \\
\hline Nevadensin $(\mathbf{2 1})$ & $\mathrm{OH}$ & $\mathrm{OCH}_{3}$ & $\mathrm{OH}$ & $\mathrm{OCH}_{3}$ & $\mathrm{H}$ & $\mathrm{OCH}_{3}$ & $\mathrm{H}$ \\
\hline
\end{tabular}

in the full scan MS (Figure 1, for instance) and mainly the notable similarities between the dissociation profiles of such isomeric compounds did not allow an unequivocal attribution. As a consequence, an exclusive image (by means of DESI-MS/MS) for each isomer could not be generated.

\section{Chemical images by DESI-MSI}

The DESI image of a specific compound reveals its distribution throughout a surface. In the present manuscript, a color scale from white to dark green indicates the regions of minimum (absence) and maximum content in the peppermint leaf of a given flavonoid, respectively. For instance, whereas Figures $2 \mathrm{a}$ and $2 \mathrm{~b}$ display the optical image of the peppermint leaf and imprinting, respectively, Figure $2 \mathrm{c}$ shows the spatial distribution of chrysoeriol (7), detected as the anion (deprotonated form) of $m / z 299.05625$. The chemical images for all flavonoids
(Tables 1-3) throughout the peppermint leaf is displayed in Figures 3-5. The assessment of such type of information allowed for an unprecedented visualization of the spatial distribution of each one of these flavonoids, which are key components of well-known biosynthetic routes (the naringenin, luteolin and apigenin routes) in plants. As a consequence, the sites of preferential occurrence of each one of these flavonoids in a peppermint leaf could be promptly assessed.

Metabolic pathways for the biosynthesis of flavonoids: the naringenin, luteolin and apigenin routes

The information regarding the main metabolic routes for the biosynthesis of flavonoids in plants was obtained from the MetaCyc database. ${ }^{47}$ The biosynthesis of all flavonoids initiates via the so-called phenylpropanoid pathway. The first step in this sequence refers to the enzymatic conversion of phenylalanine to cinnamic acid. 


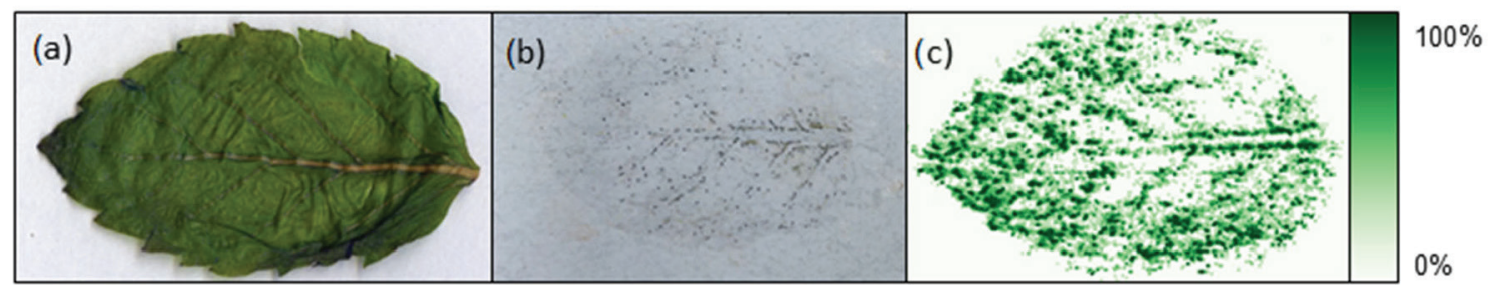

Figure 2. The optical images of (a) the peppermint leaf; (b) the resulting imprinting; and (c) the DESI image generated for the anion of $m / z 299.05625$ (deprotonated chrysoeriol (7)).

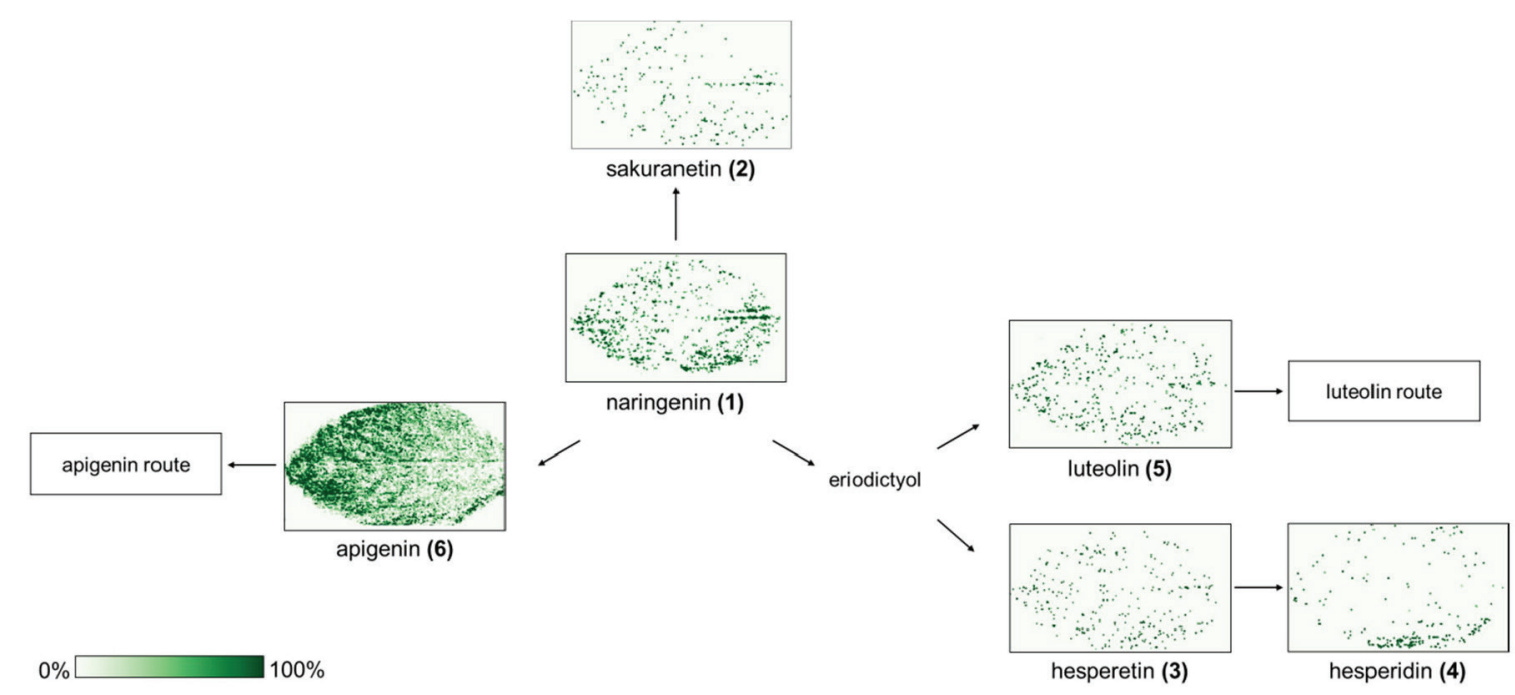

Figure 3. DESI images generated for some key metabolites (deprotonated forms) within the naringenin route.

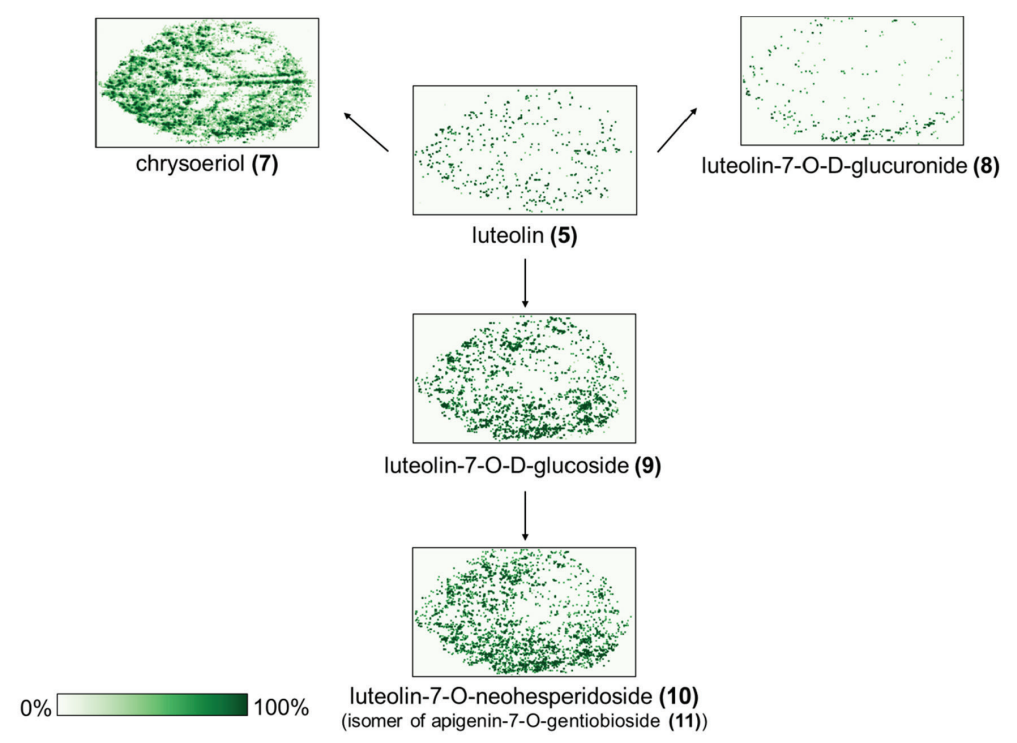

Figure 4. DESI images generated for some key metabolites (deprotonated forms) within the luteolin route.

Cinnamic acid is then hydroxylated to yield $p$-coumaric acid, which is converted to 4-coumaroyl-coenzyme-A (4-coumaroyl-CoA) by CoA. Afterwards, 4-coumaroyl$\mathrm{CoA}$ is transformed to naringenin chalcone that sequentially yields naringenin (1). ${ }^{1,3,48}$ Naringenin (1), a flavanone previously identified in peppermint leaves,, 937 is the precursor of all other flavonoid biosynthesized in plants via the naringenin, luteolin and apigenin routes (Tables 2 and 3; Figures 3-5). The subsequent discussion focuses therefore on an appraisal of the spatial distribution of each one of these flavonoids in the peppermint leaf within each biosynthetic route. 


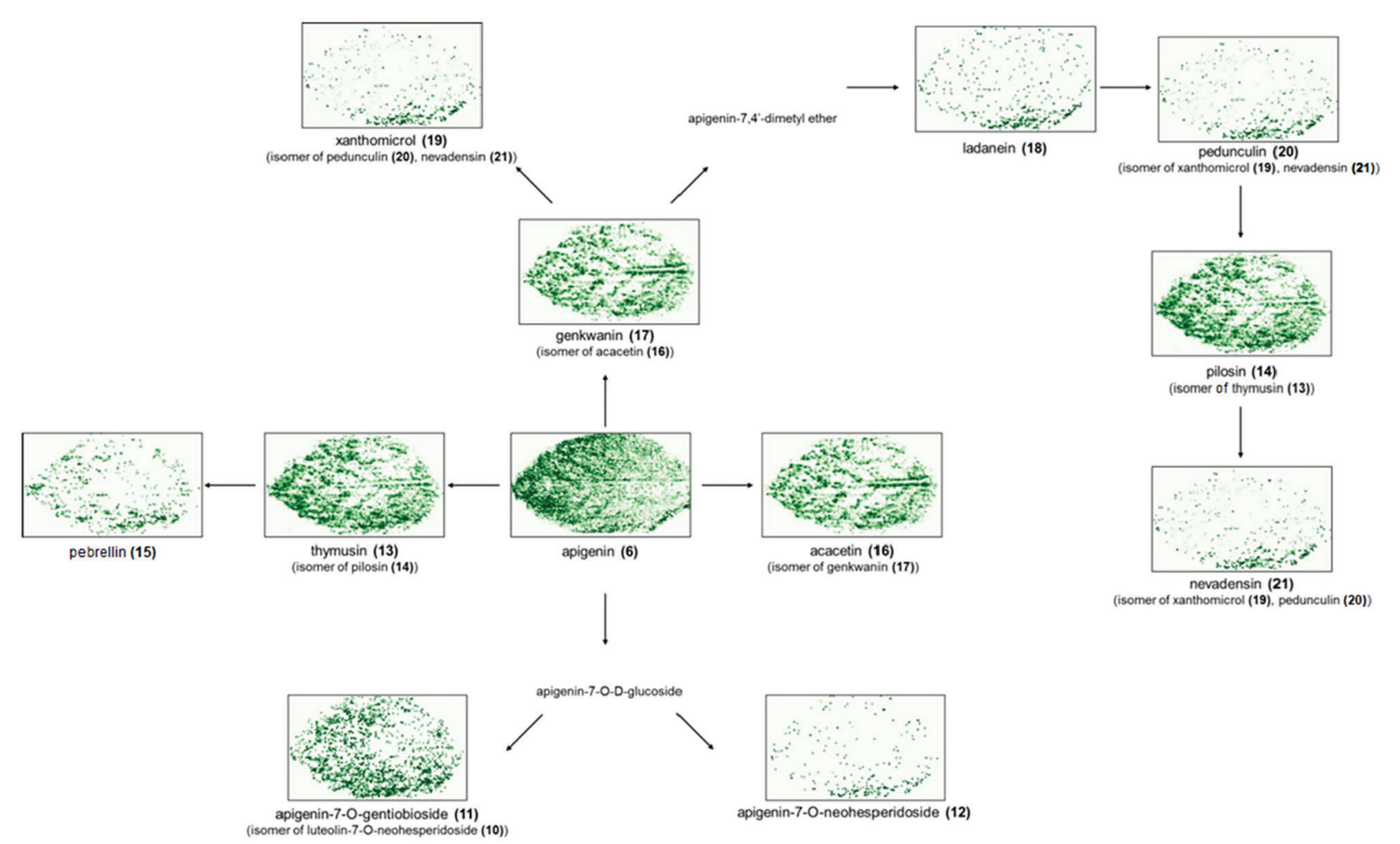

Figure 5. DESI images generated for some key metabolites (deprotonated forms) within the apigenin route.

\section{Naringenin route}

The DESI image generated for naringenin (1) reveals that although this flavonoid is distributed throughout the whole leaf, it is less concentrated at the central portion (Figure 3). In plants, naringenin (1) has some crucial functions, as it stimulates the colonization roots by some bacteria species. ${ }^{49}$ In humans, naringenin (1) presents a neuroprotective and antiteratogenic effects. ${ }^{50}$ Figure 3 shows three flavonoids that are biosynthesized in sequence within the naringenin route: sakuranetin (2), eriodictyol, which originates luteolin (5) and hesperetin (3), and apigenin (6).

Sakuranetin (2) acts as a defense agent and its concentration increases as a result of an external attack. ${ }^{49-51}$ Although this flavanone has been found in plants of the Lamiaceae family ${ }^{40,52-54}$ and in extracts of aerial parts of Mentha pulegium, ${ }^{40}$ its presence in the Mentha $\times$ piperita leaves has not been previously reported. The chemical image reveals that the flavanone sakuranetin (2) is found dispersed throughout the leaf (Figure 3). The flavanone eriodictyol, one of the biosynthesized metabolite within the naringenin route, has been frequently detected in Mentha $\times$ piperita leaves. ${ }^{6,10,12,16,17}$ Despite that, no suitable DESI image was achieved for such metabolite, but its presence was verified in the MS of the leaves methanolic extract acquired via DI-ESI-MS (a comparison between the results obtained by DESI-MSI and DI-ESI-MS is provided later in this manuscript). An opposite result was verified for hesperetin (3) and hesperidin (4), two flavanones derived from eriodictyol. The DESI image for hesperetin (3) (Figure 3) indicates that this flavanone is found as isolated spots throughout the leaf. Hesperidin (4), formed by binding hesperetin $(\mathbf{3})$ with a rutinoside, has been detected in peppermint leaves. ${ }^{12,16,17,19,37,55}$ Its DESI image reveals the presence of spots mainly concentrated at the leaf borders (Figure 3).

\section{Luteolin route}

The flavone luteolin (5), directly derived from eriodictyol (see Figure 3, naringenin route, and Figure 4, luteolin route), is the most abundant flavonoid from peppermint leaves. ${ }^{6,10,16,17,37,39,55,56}$ In plants, luteolin (5) is an active agent against radiation, ${ }^{1}$ whereas in humans it has antitumor, anti-inflammatory, analgesic and antiviral properties. ${ }^{3,11}$ Luteolin (5) undergoes methylation to form the flavone chrysoeriol (7), whose presence in extracts of Mentha spicate was previously described by Padmini et al. ${ }^{57}$ It has been reported that chrysoeriol (7) possesses antimicrobial and anti-inflammatory activities. ${ }^{57,58}$ Alternatively, luteolin (5) binds to glycosides to yield two derivatives, i.e., luteolin-7- $O$-D-glucuronide (8) and luteolin-7-O-D-glucoside (9). ${ }^{10,16,55}$ These former 
metabolites play an important role in plants since they protect them against radiation. ${ }^{5}$ In sequence, luteolin7-O-D-glucoside $(\mathbf{9})$ is enzymatically converted to luteolin7-O-neohesperidoside (10). ${ }^{56}$ The DESI images obtained for the flavonoids within the luteolin route, i.e., luteolin (5), chrysoeriol (7), luteolin-7-O-D-glucuronide (8), luteolin7-O-D-glucoside (9) and luteolin-7- $O$-neohesperidoside (10), are shown in Figure 4. Maybe because luteolin (5) is the precursor within this route, its intensity is smaller than the other ones. Luteolin (5) is homogeneously distributed throughout the whole leaf. Conversely, chryoseriol (7) is found at high contents in the midrib (main vein), lateral veins and leaf borders. The chemical image attributed to luteolin-7-O-D-glucuronide $(\mathbf{8})$ indicates that this flavonoid is found in few spots, located mainly at the leaf borders. On the other hand, the chemical image for luteolin-7-O-D-glucoside (9) reveals that this metabolite is mainly located at the leaf blade. Finally, for the luteolin7-O-neohesperidoside (10) metabolite, a similar result was achieved: its chemical image shows that this flavonoid is also found at the leaf blade but not at the leaf veins.

\section{Apigenin route}

Apigenin (6), a flavone directly derived from naringenin (1) (Figure 3), is one of the major flavonoids present in peppermint leaves. ${ }^{12,16-18,38,39} \mathrm{In}$ plants, apigenin (6) is a crucial agent for growth regulation and protection against herbivores. ${ }^{3,5}$ In humans, apigenin (6) relieves the symptoms caused by diseased livers and also functions as an antibacterial, anti-inflammatory and anti-viral agent. ${ }^{3}$ Apigenin (6) originates many other flavonoids by an extensive biosynthetic pathway within the so-called apigenin route (Figure 5). The DESI image seems to corroborate these literature data, $12,16-18,38,39$ as it reveals that apigenin $(\mathbf{6})$ is present in all leaf surface, although at higher concentrations at the tip and borders than in any other leaf section. Note also that the lateral veins are clearly discernible in this image. Sequentially in this route, apigenin-7-O-D-glucoside (9), whose occurrence in plants has been reported, ${ }^{19}$ is biosynthesized. For this metabolite, a sharp DESI image could not be obtained, although its presence has been observed in the DI-ESI-MS, as will be exposed later in this manuscript. In contrast, its glycosylated derivatives, apigenin-7- $O$-neohesperidoside (12) and apigenin-7-Ogentiobioside (11), which are metabolites of protection against ultraviolet radiation, ${ }^{5}$ furnished clear DESI images (Figure 5). Note that whereas apigenin-7-O-gentiobioside (11) is detectable with high intensities mainly at the leaf blade, apigenin-7- $O$-neohesperidoside (12) is noticeable in just few isolated spots, mostly at the leaf borders (Figure 5).
The flavone thymusin (13), directly derived from apigenin $(\mathbf{6}),{ }^{59}$ gives rise to the flavone pebrellin (15). The presence of these two flavones in the Mentha $\times$ piperita $\mathrm{L}$. leaves has been previously reported. ${ }^{6,12,38,39}$ The DESI images of both flavones indicate that whereas thymusin (13) is distributed throughout the whole surface, but mainly concentrated at the lateral veins and midrib, pebrellin (15) is mostly located at the leaf borders.

In a parallel sequence, the isomeric metabolites genkwanin (17) and acacetin (16) are directly derived from apigenin (6). Genkwanin (17) is the precursor of two distinct flavones, xanthomicrol (19) ${ }^{59}$ and ladanein (18), both previously observed in peppermint leaves. ${ }^{38,39}$ Ladanein (18) is formed via apigenin-7,4'-dimethyl ether, an undetectable intermediate. ${ }^{47}$ In plants, xanthomicrol (19) has a protective action against ultraviolet radiation, whereas in humans it has been used in the treatment of some types of cancer. ${ }^{59}$ The DESI images (Figure 5) for genkwanin (17) and ladanein (18) show that both flavonoids are scattered throughout the whole leaf, but concentrated in isolated spots. Ladanein (18) generates pedunculin (20), an isomeric metabolite of xanthomicrol (19), that leads to pilosin (14), a thymusin (13) isomer. Finally, pilosin (14) produces nevadensin (21), which is an isomeric metabolite of pedunculin (20) and xanthomicrol (19).

\section{DESI-MSI vs. DI-ESI-MS}

The absolute intensities of the deprotonated flavonoids as read in the MS obtained via DESI-MSI is much lower than those acquired by DI-ESI-MS. To enable a prompt comparison, the absolute intensities of such anions in DESI-MSI were multiplied by a factor of 15 . A plot comparing the absolute intensities of each flavonoid as a function of the technique used is displayed in Figure 6.

The results reveal that the responses for the lower-mass flavonoids $(100<m / z<350$ : apigenin (6), naringenin (1), acacetin (16)/genkwanin (17), luteolin (5), sakuranetin (2), chrysoeriol (7), hesperetin (3), ladanein (18), thymusin (13)/ pilosin (14), xanthomicrol (19)/pedunculin (20)/ nevadensin (21)) in both techniques are roughly proportional. However, this is not the case for the highermass flavonoids $(350<m / z<1000$ : pebrellin $(\mathbf{1 5})$, luteolin7-O-D-glucoside (9), luteolin-7- $O$-D-glucuronide (8), apigenin-7- $O$-neohesperidoside (12), apigenin7-O-gentiobioside (11)/luteolin-7- $O$-neohesperidoside (10), hesperidin (4)), for which the DI-ESI-MS responses are proportionally much higher than those from DESI-MSI. This is probably due to the increasing difficulty of the desorption of the higher-mass analytes from the imprinting surface. Finally, eriodictyol and apigenin-7-O-D-glucoside (small 


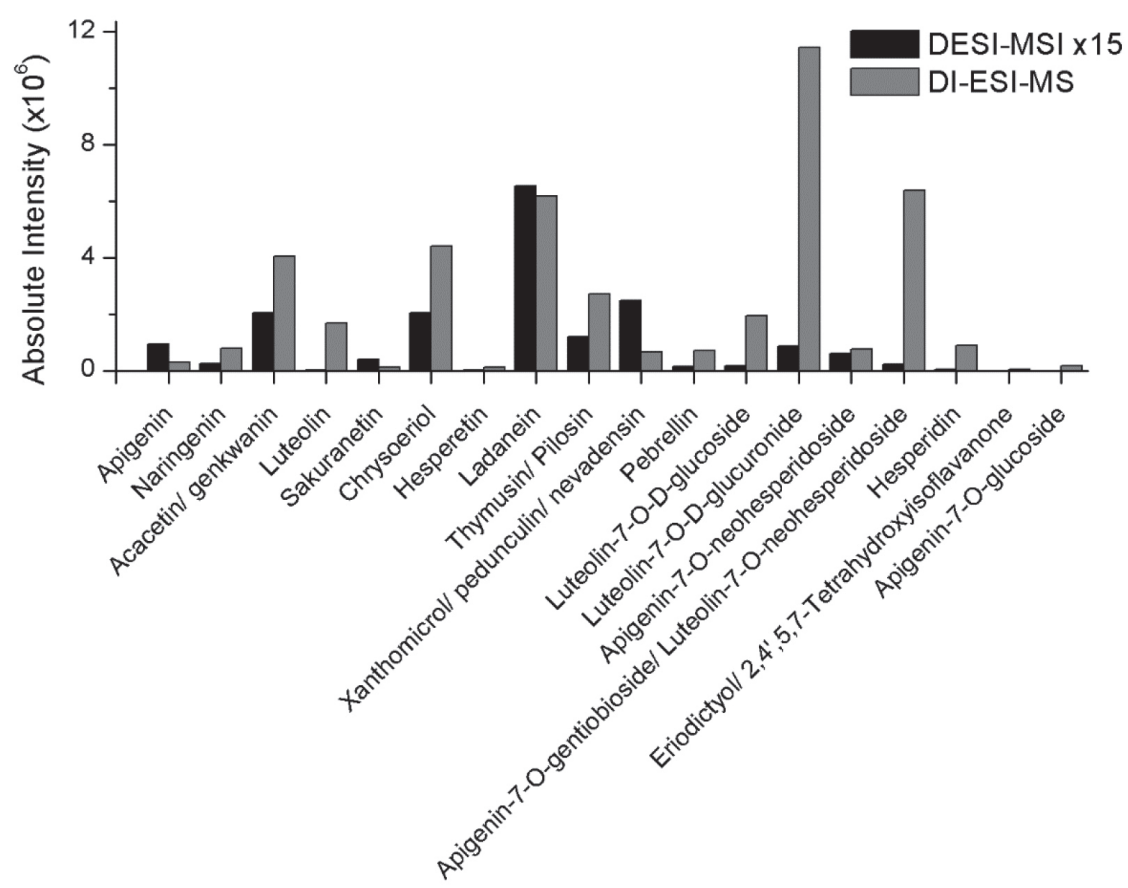

Figure 6. Comparison between the absolute intensities of the deprotonated flavonoids as read in the MS obtained via DESI-MSI and DI-ESI-MS. To enable a prompt comparison, the absolute intensities of such anions in DESI-MSI were multiplied by a factor of 15 .

and large flavonoids, respectively), were exclusively detected in the leaf methanolic extract by the DI-ESI-MS technique.

\section{Conclusions}

Flavonoids are the most important secondary metabolites in plants and have been extensively studied. The present manuscript demonstrates that DESI-MSI furnishes unprecedented and unique information regarding the spatial distribution of some key flavonoids in a plant tissue (leaves of Mentha $\times$ piperita $\mathrm{L}$.). The results presented herein can reveal the main sites where a specific metabolite is located in a plant tissue. Among other exciting possibilities, this information can be important, for instance, to increase the extraction yield of a given metabolite. Finally, similar studies with plants of distinct species are underway in our laboratory.

\section{Supplementary Information}

Supplementary data are available free of charge at http://jbcs.sbq.org.br as PDF file.

\section{Acknowledgments}

This work had financial support from the following Brazilian agencies: Conselho Nacional de Desenvolvimento Científico e Tecnológico (CNPq), Coordenação de Aperfeiçoamento de Pessoal de Nível Superior (CAPES),
Fundação de Amparo à Pesquisa de Minas Gerais (FAPEMIG) and Universidade Federal de Minas Gerais (UFMG).

\section{References}

1. Ferreyra, M. L. F.; Rius, S. P.; Casati, P.; Front. Plant Sci. 2012, $3,222$.

2. Crozier, A.; Clifford, M. N.; Ashihara, H.; Plant Secondary Metabolites: Occurrence, Structure and Role in the Human Diet; Blackwell Publishing: Oxford, 2006.

3. Kumar, S.; Pandey, A. K.; Sci. World J. 2013, 2013, 162750.

4. Kim, B.-G.; Sung, S. H.; Chong, Y.; Lim, Y.; Ahn, J.-H.; J. Plant Biol. 2010, 53, 321.

5. Mierziak, J.; Kostyn, K.; Kulma, A.; Molecules 2014, 19, 16240.

6. Riachi, L. G.; de Maria, C. A.; Food Chem. 2015, 176, 72.

7. Nguyen, T. K.; Jamali, A.; Grand, E.; Morreel, K.; Marcelo, P.; Gontier, E.; Dauwe, R.; Phytochemistry 2017, 144, 127.

8. Colombo, P. S.; Flamini, G.; Rodondi, G.; Giuliani, C.; Santagostini, L.; Fico, G.; Phytochemistry 2017, 143, 132.

9. Figueroa-Perez, M. G.; Rocha-Guzman, N. E.; Mercado-Silva, E.; Loarca-Pina, G.; Reynoso-Camacho, R.; Food Chem. 2014, 156, 273.

10. Dorman, H. J. D.; Koşar, M.; Kahlos, K.; Holm, Y.; Hiltunen, R.; J. Agric. Food Chem. 2003, 51, 4563.

11. McKay, D. L.; Blumberg, J. B.; Phytother. Res. 2006, $20,619$.

12. Mimica-Dukic, N.; Bozin, B.; Curr. Pharm. Des. 2008, 14, 10.

13. Areias, F. M.; Valentão, P.; Andrade, P. B.; Ferreres, F.; Seabra, R. M.; Food Chem. 2001, 73, 307. 
14. Murata, K.; Nakao, K.; Moriyama, K.; Fujita, T.; Matsuda, H.; J. Tradit. Med. 2013, 30, 140.

15. Duband, F.; Carnat, A. P.; Carnat, A.; Petitjean-Freytet, C.; Clair, G.; Lamaison, J. L.; Ann. Pharm. Fr. 1992, 50, 146.

16. Fecka, I.; Turek, S.; J. Agric. Food Chem. 2007, 55, 10908.

17. Koşar, M.; Dorman, H. J. D.; Başer, K. H. C.; Hiltunen, R.; J. Agric. Food Chem. 2004, 52, 5004.

18. Voirin, B.; Bayet, C.; Faure, O.; Jullien, F.; Phytochemistry 1999, 50, 1189.

19. Guedon, D. J.; Pasquier, B. P.; J. Agric. Food Chem. 1994, 42, 679.

20. Freitas, J. R. L.; Vendramini, P. H.; Melo, J. O. F.; Eberlin, M. N.; Augusti, R.; J. Braz. Chem. Soc. 2018, 29, 17.

21. Cabral, E. C.; Mirabelli, M. F.; Perez, C. J.; Ifa, D. R.; J. Am. Soc. Mass Spectrom. 2013, 24, 956.

22. Gerbig, S.; Brunn, H. E.; Spengler, B.; Schulz, S.; Anal. Bioanal. Chem. 2015, 407, 7379.

23. Hemalatha, R. G.; Pradeep, T.; J. Agric. Food Chem. 2013, 61, 7477.

24. Li, B.; Bjarnholt, N.; Hansen, S. H.; Janfelt, C.; J. Mass Spectrom. 2011, 46, 1241.

25. Li, B.; Knudsen, C.; Hansen, N. K.; Jorgensen, K.; Kannangara, R.; Bak, S.; Takos, A.; Rook, F.; Hansen, S. H.; Moller, B. L.; Janfelt, C.; Bjarnholt, N.; Plant J. 2013, 74, 1059.

26. Muller, T.; Oradu, S.; Ifa, D. R.; Cooks, R. G.; Krautler, B.; Anal. Chem. 2011, 83, 5754.

27. Tata, A.; Perez, C. J.; Hamid, T. S.; Bayfield, M. A.; Ifa, D. R.; J. Am. Soc. Mass Spectrom. 2015, 26, 641.

28. Li, B.; Hansen, S. H.; Janfelt, C.; Int. J. Mass Spectrom. 2013, 348,15 .

29. Dong, Y.; Guella, G.; Franceschi, P.; Rapid Commun. Mass Spectrom. 2016, 30, 711.

30. Kato, L.; Moraes, A. P.; de Oliveira, C. M. A.; Vaz, B. G.; Gonçalves, L. A.; Silva, E. C.; Janfelt, C.; Phytochem. Anal. 2018, 29, 69.

31. Kumara, P. M.; Srimany, A.; Ravikanth, G.; Shaanker, R. U.; Pradeep, T.; Phytochemistry 2015, 116, 104.

32. Cooks, R. G.; Ouyang, Z.; Takats, Z.; Wiseman, J. M.; Science 2006, 311, 1566.

33. Ifa, D. R.; Wiseman, J. M.; Song, Q.; Cooks, R. G.; Int. J. Mass Spectrom. 2007, 259, 8.

34. Wu, C.; Dill, A. L.; Eberlin, L. S.; Cooks, R. G.; Ifa, D. R.; Mass Spectrom. Rev. 2013, 32, 218.

35. Takats, Z.; Wiseman, J. M.; Gologan, B.; Cooks, R. G.; Science 2004, 306, 471.

36. Janfelt, C. In Mass Spectrometry Imaging of Small Molecules, Methods in Molecular Biology, vol. 1203; He, L., ed.; Humana Press: New York, 2015. DOI: 10.1007/978-1-4939-1357-2_9.

37. Figueroa-Perez, M. G.; Rocha-Guzman, N. E.; Perez-Ramirez, I. F.; Mercado-Silva, E.; Reynoso-Camacho, R.; J. Agric. Food Chem. 2014, 62, 12027.
38. Voirin, B.; Bayet, C.; Phytochemistry 1992, 31, 2299.

39. Voirin, B.; Saunois, A.; Bayet, C.; Biochem. Syst. Ecol. 1994, 22,95 .

40. Taamalli, A.; Arraez-Roman, D.; Abaza, L.; Iswaldi, I.; Fernandez-Gutierrez, A.; Zarrouk, M.; Segura-Carretero, A.; Phytochem. Anal. 2015, 26, 320.

41. Chernonosov, A. A.; Karpova, E. A.; Lyakh, E. M.; Rev. Bras. Farmacogn. 2017, 27, 576.

42. Brito, A.; Ramirez, J. E.; Areche, C.; Sepulveda, B.; Simirgiotis, M. J.; Molecules 2014, 19, 17400.

43. Fabre, N.; Rustan, I.; Hoffmann, E. D.; Quetin-Leclercq, J.; J. Am. Soc. Mass Spectrom. 2001, 12, 9.

44. Peter, S. R.; Peru, K. M.; Fahlman, B.; McMartin, D. W.; Headley, J. V.; J. Environ. Sci. Health, Part B 2015, 50, 819.

45. Yin, R.; Han, F.; Tang, Z.; Liu, R.; Zhao, X.; Chen, X.; Bi, K.; J. Pharm. Biomed. Anal. 2013, 72, 127.

46. Simões, C. M. O.; Schenkel, E. P.; Gosmam, G.; Mello, J. C. P.; Mentz, L. A. P.; Petrovick, R.; Farmacognosia: da Planta ao Medicamento, $6^{\mathrm{a}}$ ed.; Artmed: Porto Alegre, 2018.

47. Caspi, R.; Altman, T.; Billington, R.; Dreher, K.; Foerster, H.; Fulcher, C. A.; Holland, T. A.; Keseler, I. M.; Kothari, A.; Kubo, A.; Krummenacker, M.; Latendresse, M.; Mueller, L. A.; Ong, Q.; Paley, S.; Subhraveti, P.; Weaver, D. S.; Weerasinghe, D.; Zhang, P.; Karp, P. D.; Nucleic Acids Res. 2014, 42, D459.

48. Forkmann, G.; Martens, S.; Curr. Opin. Biotechnol. 2001, 12, 155.

49. Treutter, D.; Environ. Chem. Lett. 2006, 4, 147.

50. Trivellini, A.; Lucchesini, M.; Maggini, R.; Mosadegh, H.; Villamarin, T. S. S.; Vernieri, P.; Mensuali-Sodi, A.; Pardossi, A.; Ind. Crops Prod. 2016, 83, 241.

51. Kodama, O.; Miyakawa, J.; Akatsuka, T.; Kiyosawa, S.; Phytochemistry 1992, 31, 3807.

52. Guillén, M. D.; Manzanos, M. J.; Food Chem. 1998, 63, 373.

53. Lucena, H. F. S.; Madeiro, S. A. L.; Siqueira, C. D.; BarbosaFilho, J. M.; Agra, M. F.; Silva, M. S.; Tavares, J. F.; Helv. Chim. Acta 2013, 96, 1121.

54. Kharazian, N.; Acta Bot. Bras. 2014, 28, 281.

55. Inoue, T.; Sugimoto, Y.; Masuda, H.; Kamei, C.; Biol. Pharm. Bull. 2002, 25, 256.

56. Gao, B.; Lu, Y.; Qin, F.; Chen, P.; Shi, H.; Charles, D.; Yu, L. L.; J. Agric. Food Chem. 2012, 60, 11987.

57. Padmini, E.; Valarmathi, A.; Rani, M. U.; Asian J. Exp. Biol. Sci. 2010, $1,10$.

58. Williams, C. A.; Harborne, J. B.; Geiger, H.; Hoult, J. R. S.; Phytochemistry 1999, 51, 417.

59. Mohammad, F.; Rosa, M. C.; Abbas, K.; Mercedes, B.; Javier, P.; Mini-Rev. Med. Chem. 2014, 14, 725.

Submitted: September 14, 2018

Published online: March 8, 2019 